\title{
Shock-elicited aggression: Its displacement by a passive social orientation avoidance response
}

\author{
ROBERT SBORDONE and JOHN GARCIA \\ Neuropsychiatric Institute, University of California, Los Angeles, California 90024 \\ and \\ BROOKS CARDER \\ Synanon Foundation, Marshall, Califormia 94940
}

\begin{abstract}
Rats received shock contingent upon their social orientation to each other in a shock-elicited aggression situation. They could either fight or avoid shock by assuming a particular passive social orientation posture with respect to each other. Rather than fight, the rats quickly acquired the appropriate social orientation posture that prevented shock delivery. The results indicate that fighting should not be considered a prepotent response to pain elicited by shock in the presence of another animal of the same species.
\end{abstract}

Several investigators have demonstrated that rats trained alone in a compartment to avoid shock by leverpressing (Powell, Francis, Francis, \& Schneiderman, 1972; Ulrich, 1967; Ulrich \& Craine, 1964; Ulrich, Stachnik, Brierton, \& Mabry, 1969) or wheel turning (Logan \& Boice, 1969) will engage in fighting when another rat is introduced into the experimental situation rather than continue the instrumental avoidance response, even though this results in the delivery of many more shocks. This finding might easily lead to the interpretation that fighting occurs because it is a more natural response to aversive stimulation than is an instrumental avoidance when there is more than one rat present. This is similar to the notion of "instinctive drift," where instrumentally trained behaviors break down and regress in the direction of more natural responses, even to the delay or preclusion of reinforcement (Breland \& Breland, 1961).

In a series of studies, we examined empirically the question of whether fighting would displace any and all instrumental avoidance behaviors. These studies suggested that in rats an avoidance response consisting of a passive social orientation posture was prepotent to fighting. In the present study we allowed this response to serve as our instrumental shock avoidance response. A pair of rats was placed in a small chamber and shocked. They had the opportunity to fight or to avoid shock by assuming a particular passive social orientation posture with respect to each other.

This research was supported in part by USPHS Grant DA00288 to Brooks Carder. We gratefully acknowledge the assistance of Roseann Giarusso and Gary Fradkin, and the helpful suggestions of Professor Eric Holman. Requests for reprints should be sent to the first author.

\section{METHOD}

\section{Subjects}

Thirty-two experimentally naive male Sprague-Dawley rats, over 100 days old, were obtained from the Simonsen Breeding Laboratory, Gilroy, California. They were housed in individual cages with food and water available at all times.

\section{Apparatus}

Two identical cylindrical Plexiglas chambers $(30 \mathrm{~cm}$ in diam $x 37.5 \mathrm{~cm}$ high) were used for aggression testing. The floor of each chamber was of .634-cm stainless steel rods spaced $1.27 \mathrm{~cm}$ apart. Shocks were delivered to the animals through floor grids from a constant-current source, operating through a Davis Model 255 grid scrambler. The duration of shock and the minimal interval between shocks were automatically regulated by a series of timers. Each fight made by a pair of subjects was recorded on digital counters.

\section{Procedure}

Rats were weighed at the beginning of the experiment and paired together on the basis of equal or similar body weight. Each pair was then randomly assigned to either a test or control group. A pair of rats from the test group was placed in one of the experimental chambers for aggression testing. Half of the test-group pairs received shock when either or both members of the pair were facing or oriented toward the head or front torso of the other member (facing-toward condition). The remaining half received shock when neither rat was facing or oriented toward the other (facing-away condition). All test pairs were tested first in one orientation condition and then, immediately following this, in the other. Eight pairs of rats served as yoked controls and received shock in the remaining experimental chamber whenever the test rats were shocked.

Both test and control pairs received electric shock of $2.0-\mathrm{mA}$ intensity for a 1.5-sec duration when the experimenter depressed a microswitch. A timer, however, prevented the subjects from receiving shocks less than $5 \mathrm{sec}$ apart. The orientation conditions were switched after each test pair had received 50 shocks or after $25 \mathrm{~min}$ had elapsed since the delivery of the first shock in that particular orientation condition, whichever came first. The experimental session ended when each test pair had been tested in the two orientation conditions. 
Fighting was recorded by two observers who had considerable experience observing shock-induced fighting. The first observer depressed a microswitch when either or both rats in the first experimental chamber struck or bit each other. The second observer depressed a microswitch when either or both rats in the the second experimental chamber did the same. Neither observer was aware of the particular orientation condition to which a pair of rats belonged or of the purpose of the experiment. The behavior of both test and control pairs throughout the entire experimental session was observed by the experimenter on a SONY closed-circuit television screen. Each observer was prevented from viewing either the other observer's experimental chamber or the experimenter's behavior. The experimenter was also prevented from viewing either observer.

\section{RESULTS}

When rats initially received shock for facing toward each other, they either fought or attempted to escape from each other. After several shocks, these behaviors were replaced by postures in which each rat stood frozen in an opposite direction, completely away from the other. The postures prevented further shocks. However, after several minutes, one of the rats would gradually turn in the direction of the other, causing both to receive shock. Upon receiving shock, they either fought or tried to escape from each other. These behaviors again gave way to the freezing postures the rats had adopted earlier. These postures were maintained throughout the remainder of the orientation condition and prevented the pairs from receiving further shock. When the rats were then shocked while facing away from each other, they rapidly transferred the orientation response set acquired in the previous condition to the new orientation condition. They generally fought when shock was initially delivered, but after a few shocks they stood frozen, facing toward each other in either a crouched or upright position. The postures prevented further shocks and were rigidly maintained until the experimental session terminated.

When rats initially received shock for facing away from each other, they either fought or attempted to escape from the apparatus. Fighting, if it occurred, disappeared after a single bout and was replaced by attempts to escape from the apparatus. After several shocks, their escape behavior was replaced by postures in which both rats stood frozen, facing each other in either a crouched or an upright position. These postures prevented further shocks and were rigidly maintained until the next orientation condition began. When the rats were next shocked for facing toward each other, they rapidly transferred the passive orientation response acquired in the previous orientation to the new condition. After receiving one or two shocks, each rat faced in an opposite direction, or completely away from the other. These postures prevented further shocks and were maintained until the experimental session terminated. Fighting was never observed to occur during this orientation condition in these subjects.
Figure 1 presents the time to avoid shock for both test groups as a function of the order of testing. It is apparent that rats tested in the second orientation condition, regardless of the type of initial orientation, required less time to adopt postures that prevented shock delivery. This effect was highly reliable as revealed by a two-factor analysis of variance with repeated measures $[F(1,6)=12.74, p<.012]$. No difference was found between the means of the two test groups in either orientation condition $[F(1,6)=3.31, p<.119]$. Thus, subjects appeared to develop an avoidance learning set in the first orientation condition which enabled them to quickly avoid shock when they were tested in the second orientation condition. There was no significant difference, however, between the orientation conditions with respect to rate of avoidance acquisition.

The initial orientation in which a pair of rats received shock was a major factor in determining the probability of fighting. Rats initially shocked for facing toward each other tended to engage in a higher proportion of fights to shocks than did their yoked controls $(t=2.26$, $\mathrm{df}=6, \mathrm{p}<.06$, two-tailed test). No difference, however, was found between these rats and their yoked controls during the second orientation condition $(t=.11)$. On the other hand, rats initially shocked when they were facing away from each other engaged in a considerably lower proportion of fights to shocks than did their

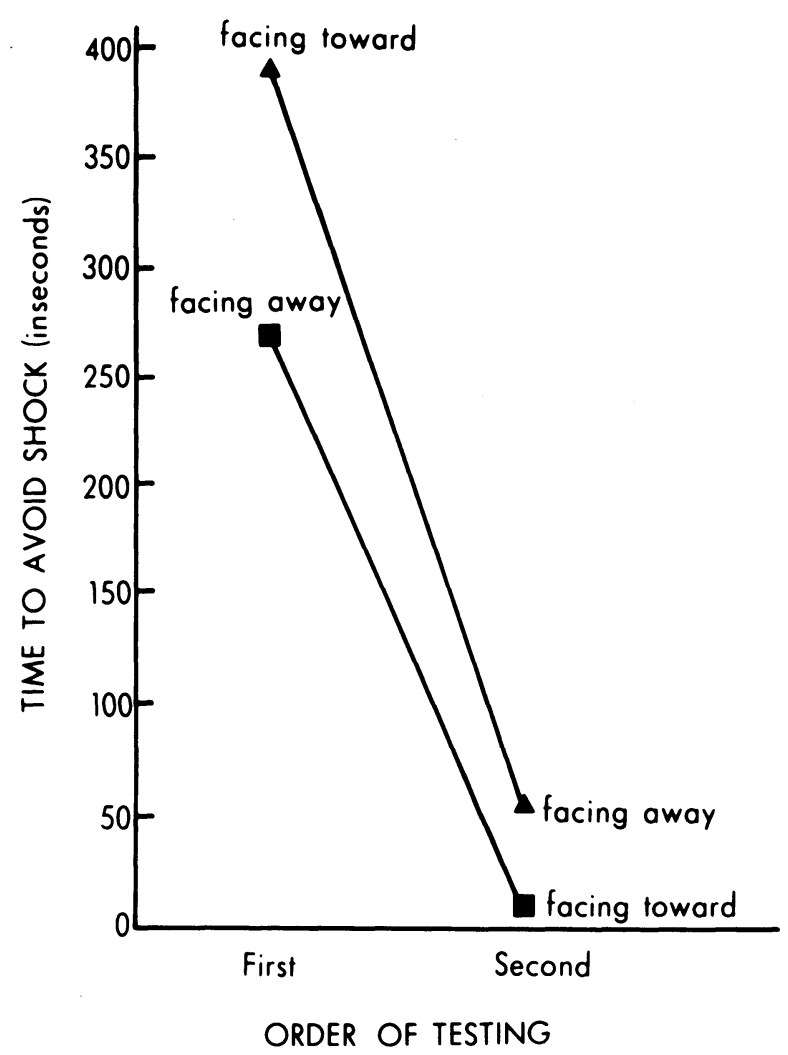

Figure 1. Mean time required for both orientation groups to avoid shock in each testing period. 
yoked controls $(t=4.13, \mathrm{df}=6, \mathrm{p}<.01)$. These rats also engaged in a lower proportion of fights to shocks than their yoked controls when they were shocked for facing toward each other, although this difference was not statistically reliable $(\mathrm{t}=1.64, \mathrm{df}=6, \mathrm{p}<.15)$.

\section{DISCUSSION}

The present data limit the generality of the conclusion that aggressive behavior will always displace avoidance behavior, since our results indicate that avoidance behavior will replace fighting as a result of shock. When rats were facing toward or facing away from each other, they froze in a passive social orientation posture relative to each other following shock. These postures rapidly displaced fighting and, also, kept the rats from attempting active avoidance responses, such as running or jumping. Thus, it appears that the type of avoidance response is crucial in determining which behavior will ultimately predominate. It has been pointed out that behaviors which are similar to the organism's species-specific defense reactions (SSDR) of flight, freezing, and threat are behavior that will be most easily learned in an avoidance situation (Bolles, 1970). Behaviors such as leverpressing or wheel turning are not SSDRs and are easily displaced by aggression even when the aggressive behavior does not lead to shock avoidance. In the present study, freezing, an SSDR, is an effective avoidance behavior, as long as the freezing is carried out in the appropriate orientation. Under this circumstance, the avoidance behavior of freezing rapidly displaced aggressive behavior. Thus, our results indicate that fighting should not be considered the prepotent response to pain elicited by shock in the presence of another animal of the same species.

\section{REFERENCES}

Bolles, R. C. Species-specific defense reactions and avoidance learning. Psychological Review, 1970, 77, 32-48.

Breland, K., \& Breland, M. The misbehavior of organisms. American Psychologist, 1961, 61, 681-684.

Logan, F. A., \& BoICE, R. Aggressive behaviors of paired rodents in an avoidance context. Behaviour, 1969, 34, 161-183.

Powell, D. A., Francis, M. J., Francis, J., \& SCHNEIDERman, N. Shock-induced aggression as a function of prior experience with avoidance, fighting, or unavoidable shock. Journal of the Experimental Analysis of Behavior, 1972, 18, 323-332.

UlRICH, $R$. Interaction between reflexive fighting and cooperative escape. Journal of the Experimental Analysis of Behavior, 1967, 10, 311-317.

Ulrich, R. E., \& Craine, W. H. Behavior: Persistence of shock-induced aggression. Science, 1964, 143, 971-973.

Ulrich, R. E., Stachnik, T. J., Brierton, G. R., \& MABRY, J. H. Fighting and avoidance in response to aversive stimulation. Behaviour, 1969, 26, 124-129.

(Received for publication November 19, 1976.) 